\title{
Development of an investment case for obesity prevention and control: perspectives on methodological advancement and evidence
}

\author{
Olga V. Milliken ${ }^{1}$ and Vivian L. Ellis ${ }^{1}$
}

Suggested citation

Milliken OV, Ellis VL, Development of an investment case for obesity prevention and control: perspectives on methodological advancement and evidence. Rev Panam Salud Publica. 2018;42:e62. https://doi.org/10.26633/RPSP.2018.62

ABSTRACT

This paper opens a discussion on the main features of an investment case for obesity prevention and control, by scanning available evidence on existing approaches and by highlighting contextual considerations and evidence for Latin America and the Caribbean. We call on researchers and analysts in the field to update and broaden existing methods of economic analyses to better reflect the multisectoral nature of an investment case for obesity prevention and control. We also identify research gaps and further work required to advance methods and evidence towards investment cases throughout the Americas.

Keywords Cost-benefit analysis; obesity; investments; health economics; health policy; Americas.

As the obesity epidemic has been spreading rapidly across the Americas, national governments and regional and international organizations have called for action from the whole of society (1-4). To answer these calls, jurisdictions are seeking comprehensive investment cases that would articulate the benefits and costs of an intervention strategy across various economic actors and the factors that could affect its implementation. For example, the United Nations Interagency Task Force on the Prevention and Control

\footnotetext{
Centre for Chronic Disease Prevention and Health Equity and WHO Collaborating Centre on Noncommunicable Disease Policy, Public Health Agency of Canada, Ottawa, Canada. Send correspondence to Olga Milliken at olga.milliken@ canada.ca
}

of Noncommunicable Diseases has been working with countries around the globe to prepare investment cases for prevention and control of noncommunicable diseases (NCDs) and their risk factors (5).

An investment case presents reasoning for an action and includes a strategy to achieve a stated objective. Drawing from recent efforts to formulate investment cases (5-7), we find that a public health investment case generally includes six steps: 1) describing the problem within a given country, including determinants and risk factors and public health and economic impacts; 2) identifying effective, feasible, and locally relevant interventions for analysis; 3) providing analysis of the costs versus benefits of intervening, and identifying synergies among interventions; 4) building a package of interventions based on the second and third steps as well as other criteria such as distributional consequences and acceptability among stakeholders; 5) identifying the funding requirements and finding resources; and 6) developing a detailed plan for implementation and evaluation of results. Figure 1 summarizes this process.

The objective of this paper is to discuss how various economic methods for valuing costs and benefits can be applied to obesity-targeted interventions (the third step listed above). The paper also summarizes major evidence towards the development of an investment case for obesity prevention and control in line with the third and fourth steps. 
FIGURE 1. Process to develop an investment case for obesity action

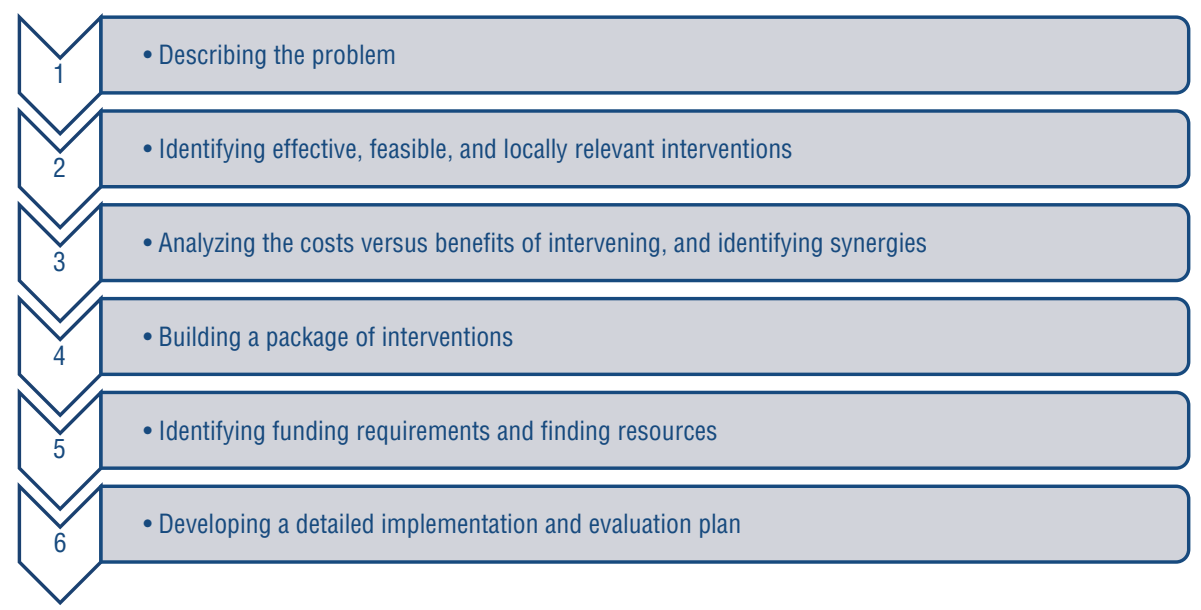

Source: Prepared by authors.

In addition, research gaps in methods and evidence are underscored, and ways forward are proposed.

It should be noted that this paper is not a systematic literature review, but rather a scoping review of methodologies and the evidence supporting them.

\section{METHODS OF ECONOMIC EVALUATION OF INTERVENTIONS}

\section{Social cost-benefit analysis as a conceptual framework}

Economic analyses can assess whether a policy response is required from the efficiency perspective. For example, the analyses can identify market failures in efficient resource allocation, as well as whether such failures are amenable to intervention (8). Further, economic evaluation, both prospective and experiential, can inform on a range of interventions. Note that in this paper we refer to an economic evaluation as either a prospective or retrospective "comparative analysis of alternative courses of action in terms of both their costs and consequences" (9).

A social cost-benefit analysis (SCBA) is a general economic framework used to examine which interventions, or intervention package, bring the highest socioeconomic return. Under SCBA, social welfare (well-being) is some measure of the well-being of all individuals in the economy. As individuals maximize their own overall well-being, rather than health alone, SCBA takes a broad perspective, under which societal health-related goals are balanced with that of the consumption of goods and services, including food, beverages, and physical activity.

In the most comprehensive case of SCBA, costs and benefits are presented in monetary units, allowing various benefits to be added together and compared with costs associated with the intervention(s). Also, using common currency allows analyses of benefits to various economic actors, including central ministries and nonhealth stakeholders. Lifetime costs and benefits are usually discounted to a base year, to assess the present value of total multiyear benefits and costs. An intervention to address obesity is desirable from a society's viewpoint if the present value of total benefits outweighs that of the intervention costs (9).

Health benefits can be described as: 1) a direct contribution to well-being (intrinsic value of health); 2) greater productivity; 3) greater longevity; and 4) greater engagement in society, including volunteering (10). A range of methods to value health or life can be employed, including a value of statistical life (VSL) approach under either a revealed preference or a contingent valuation (willingness to pay) method. In principle, a VSL approach measures all four of those health benefits.

Costs of an intervention include implementation costs, but also economic losses attributable to an intervention (such as financial losses to a food industry or job layoffs due to a labeling regulation or due to a tax). Also, resources saved in health care, enhanced productivity, etc., that are attributed to the intervention are subtracted from costs (9).

As a gold standard of economic evaluation, a comprehensive SCBA has high information requirements that may not be achievable in each practical application. Particularly, the search for methods to value benefits of improved health is ongoing, underscoring the difficulties of this task (11). The value of health cannot be directly assessed from market prices, and likely is best derived from a combination of an assessment of individual preferences and professional opinion $(9,10)$. When valuation information is incomplete or estimates vary widely, sensitivity analysis can assess the robustness of the SCBA.

\section{Applications of social cost-benefit analysis}

Based on a general SCBA framework, various applications and protocols have been developed, such as cost-utility analysis (CUA), cost-effectiveness analysis (CEA), and social return on investment (SROI) $(9,12,13)$ (Table 1). These represent versions of an SCBA that forgo comprehensiveness for tractability, standardization, or verifiability. However, by simplifying, such applications can introduce bias or ignore broad impacts.

Cost-effectiveness and cost-utility analyses. CEAs/CUAs of obesity prevention and management interventions dominate the field. They allow the comparison of costs and benefits of an intervention with that of a status quo or of a different intervention. In a health-related CEA, benefits are often measured in life years saved or changes in body mass index (BMI). In a CUA, quality-adjusted life years (QALYs) or disability-adjusted life years (DALYs) are used, which compared to a CEA, adds the quality-of-life dimension into the outcome (14). As CEAs and CUAs evaluate benefits in units of health rather than placing a society's value on these units, these analyses only account indirectly for the first and third benefits mentioned above. Also, CUAs and CEAs cannot formally integrate the second and fourth benefits.

In general, CEAs and CUAs work well when a single sector's perspective is used and intervention effects are contained within this sector, such as replacing an existing pharmaceutical with a more potent one. Despite their wide usage for in-health-sector analyses, these methods are not commonly used by other sectors (e.g., agriculture, environment, transport), even for decisions related to human health (15-17). 
TABLE 1. Characteristics of methods to inform an investment case for obesity prevention and control

\begin{tabular}{|c|c|c|c|c|c|c|}
\hline Method & Main objective & $\begin{array}{l}\text { Intervention } \\
\text { costs }\end{array}$ & $\begin{array}{l}\text { Intervention } \\
\text { benefits }\end{array}$ & $\begin{array}{l}\text { Formulation of analysis } \\
\text { results }\end{array}$ & Strengths & Weaknesses \\
\hline $\begin{array}{l}\text { Social cost-benefit } \\
\text { analysis (SCBA) }\end{array}$ & $\begin{array}{l}\text { To assess if an intervention is } \\
\text { worth the investment. }\end{array}$ & $\mathrm{C}_{1}{ }^{\mathrm{a}}$ & $W_{1}^{b}$ & $\begin{array}{l}\text { If } W_{1}+S^{c}-C_{1}>1 \text {, the } \\
\text { intervention is worth the } \\
\text { investment. }\end{array}$ & $\begin{array}{l}\text { Can account for } \\
\text { multisectoral benefits } \\
\text { and broader benefits in } \\
\text { general resulting from the } \\
\text { intervention; decision to } \\
\text { invest is based on an } \\
\text { objective score; can inform } \\
\text { resource allocation beyond } \\
\text { the health sector. }\end{array}$ & $\begin{array}{l}\text { No standard/accepted } \\
\text { approach for valuing } \\
\text { intervention benefits. }\end{array}$ \\
\hline $\begin{array}{l}\text { Cost-effectiveness } \\
\text { analysis (CEA) }\end{array}$ & $\begin{array}{l}\text { To compare costs vs. benefits } \\
\text { of an intervention with the costs } \\
\text { vs. benefits of the status quo or } \\
\text { another intervention; interventions } \\
\text { are compared within the health } \\
\text { sector, as benefits have to be } \\
\text { measured in the same units. }\end{array}$ & $\mathrm{C}_{2}{ }^{\mathrm{d}}$ & $\mathrm{E}^{\mathrm{e}}$ & $\begin{array}{l}\text { If }\left(\mathrm{C}_{2}-\mathrm{S}\right) / \mathrm{E}>\text { acceptable } \\
\text { threshold (budget } \\
\text { constraint) (e.g., } \\
\text { US } \$ 50000 / \text { year of } \\
\text { life saved), then the } \\
\text { intervention is better } \\
\text { than the alternative. }\end{array}$ & $\begin{array}{l}\text { Intervention benefits are } \\
\text { easy to obtain and are } \\
\text { readily quantifiable. }\end{array}$ & $\begin{array}{l}\text { Cannot account for } \\
\text { multisectoral intervention } \\
\text { benefits; uses a subjective } \\
\text { ratio for decision-making; } \\
\text { cannot account for benefit } \\
\text { spillovers. }\end{array}$ \\
\hline $\begin{array}{l}\text { Cost-utility analysis } \\
\text { (CUA) }\end{array}$ & Same objective as for CEA. & $\mathrm{C}_{2}$ & $U^{f}$ & $\begin{array}{l}\text { If }\left(\mathrm{C}_{2}-\mathrm{S}\right) / \mathrm{U}>\text { acceptable } \\
\text { threshold (budget } \\
\text { constraint) (e.g., } \\
\text { US\$ } 50000 / Q A L Y) \text {, then } \\
\text { the intervention is better } \\
\text { than the alternative. }\end{array}$ & $\begin{array}{l}\text { Intervention benefits are } \\
\text { relatively easy to obtain. }\end{array}$ & Same as CEA. \\
\hline $\begin{array}{l}\text { Social return on } \\
\text { investment (SROI) }\end{array}$ & $\begin{array}{l}\text { Same objective as for SCBA; } \\
\text { also to show the value of } \\
\text { investments to stakeholders. }\end{array}$ & $C_{1}$ & $W_{2}^{g}$ & $\begin{array}{l}\text { If } W_{2} / C_{1}>1 \text {, the } \\
\text { intervention is worth } \\
\text { investing in. }\end{array}$ & $\begin{array}{l}\text { Same strengths as for } \\
\text { SCBA. }\end{array}$ & $\begin{array}{l}\text { The SROI approach to public } \\
\text { health interventions is not well } \\
\text { established. There is no } \\
\text { standard approach to value } \\
\text { benefits; multiple data sources } \\
\text { are required to increase } \\
\text { trustworthiness of } \\
\text { intervention benefit estimates; } \\
\text { benefit attribution effect is } \\
\text { likely subjective; financial } \\
\text { proxies are not verified. }\end{array}$ \\
\hline $\begin{array}{l}\text { Sector and } \\
\text { macroeconomic } \\
\text { impact analyses }\end{array}$ & $\begin{array}{l}\text { Estimate the impact of an } \\
\text { intervention on sectors and } \\
\text { economy. }\end{array}$ & $\begin{array}{l}\text { Costs } \\
\text { incurred by } \\
\text { the sector } \\
\text { as a result } \\
\text { of the } \\
\text { intervention. }\end{array}$ & $\begin{array}{l}\text { Benefits to } \\
\text { the sector } \\
\text { as a result } \\
\text { of the } \\
\text { intervention. }\end{array}$ & $N A^{h}$ & $\begin{array}{l}\text { Can inform on } \\
\text { multisectoral intervention } \\
\text { benefits in SCBA. }\end{array}$ & NA \\
\hline
\end{tabular}

Source: Prepared by the authors based on $(9,12,13)$.

a $C_{1}=$ broad costs, including intervention cost to health and other sectors, and other costs associated with the intervention, e.g., cost to informal caregivers; costs are expressed in monetary units.

b $W_{1}=$ valued health and other benefits from the intervention; benefits are expressed in monetary units.

c $\mathrm{S}=$ savings in health and other sectors resulting from the intervention; savings are expressed in monetary units.

${ }^{d} \mathrm{C}_{2}=$ narrow costs, usually only intervention cost; costs are expressed in monetary units.

${ }^{e} \mathrm{E}=$ health outcomes resulting from the intervention, e.g., years of life saved or changes in body mass index (BMI).

${ }^{\dagger} \mathrm{U}=$ quality-adjusted life years (QALYs) or disability-adjusted life years (DALYs) or other health outcomes that combine quantity and quality of life gained or saved as a result of the intervention.

${ }^{g} \mathrm{~W}_{2}=$ monetized health and nonhealth outcomes (social, economic, and environmental) of the intervention; outcomes are monetized using financial proxies and stakeholder's opinion.

h $N A=$ not applicable.

Compared to the SCBA, CEA/CUA frameworks can neither account for multisectoral benefits evaluated by different metrics (e.g., dollars, QALYs, days of sick leave, years of education) in a single measure nor directly compare the costs against the benefits of an intervention to determine whether the intervention is worth pursuing. Instead, the decision regarding whether the intervention improves upon the status quo is based on a comparison with a subjective threshold of cost-effectiveness (e.g., acceptable number of dollars spent per QALY). The implications of the arbitrary nature and narrow focus of cost-effectiveness thresholds have been discussed elsewhere (9).

Social return on investment. Compared to CEA and CUA, the SROI approach has the capacity to measure broader socioeconomic and environmental benefits of interventions. Benefits to intervention beneficiaries as well as to relevant stakeholders are measured using financial proxies (13) and are compared to costs of intervening. SROI is much less commonly used for interventions in public health (12) than are CEA and CUA, and the SROI method for public health is not yet well established. Issues remain regarding whose benefits should be accounted for, the choice of financial proxies to monetize benefits, and the attribution of effects/benefits of the intervention (12).

\section{Macroeconomic analyses}

Macroeconomic models, in particular general equilibrium or partial equilibrium models, can assess sectoral and 
economy-wide costs and benefits resulting from obesity prevention interventions. They are well suited for forecasting the economy-wide or sectoral effects of interventions (18). Examples of such effects include job losses as a result of a shrinking demand for unhealthy products, impacts on trade and agriculture due to a shift in demand for certain foods, and a healthier workforce.

\section{AVAILABLE EVIDENCE OF COSTS AND BENEFITS}

\section{Evidence of the economic cost of obesity}

Although economic cost estimates alone are insufficient for developing an investment case for obesity prevention and control, they can describe the size of the pre-intervention impact of obesity as well as the potential savings as a result of intervention strategies. Unfortunately, evidence describing the economic cost of obesity for the Americas is sparse, with the exceptions of Canada and the United States of America (19). Further, the information is largely limited to impacts on health care expenditures. The most recent systematic review suggests a wide range of estimates of obesity-attributed health care costs in Latin America, from $0.1 \%$ to $14 \%$ of total health care expenditures, depending on the country and study. For example, this estimate was 3.2\% for Brazil in 2013 and 2.1\% for Chile in 2014 (20). For Canada, the most recent estimates are $1.7 \%$ (21) and $2.6 \%$ (22), whereas for the United States, the range is $5 \%$ to $10 \%(23)$.

The worldwide available evidence on productivity losses due to premature mortality and sickness absences attributed to obesity indicates that these are at least as high as health care expenditures due to obesity (24). Few of these estimates are available for the Americas, with the exception of Canada and the United States (25). Two studies for Mexico estimate productivity losses at $0.11 \%$ and $0.42 \%$ of gross domestic product (GDP), while a study for Argentina puts the figures at $0.02 \%$ of GDP (20). Other economic effects of obesity, such as impacts on social protection programs, human capital development and education, employment, and nonpaid work, have received only cursory attention $(10,26)$.

Addressing obesity is a particular challenge for countries that, until recently, have targeted undernutrition. As the epidemiological transition progresses through the Americas, many countries are now experiencing a double burden of malnutrition, where stunting and micronutrient deficiencies take place together with increasing obesity rates (27). A 2017 study by the Economic Commission for Latin America and the Caribbean (ECLAC) and the World Food Program (WFP) found that in Ecuador and Mexico, respectively, the economic burden of malnutrition (lost productivity, reduced schooling, and elevated health care expenditures) is $4.3 \%$ and $2.3 \%$ of GDP. In these two countries, the burden of malnutrition is comprised mostly of losses due to stunting, which remain 1.5 to 3 times higher than that due to overnutrition/overweight. In contrast, the ECLAC/WFP study found that, while stunting is considered eradicated in Chile, the country faces a rising economic burden of overnutrition/overweight, representing $0.2 \%$ of GDP (28). Moreover, adverse obesity outcomes may be worsened by associated deficiencies of iron, vitamin B12, vitamin D, and other micronutrients $(29,30)$, impacting disease progression and health care costs.

Although alarming, the obesity cost estimates presented above do not in themselves guide decisionmakers to an acceptable, feasible, efficient policy response. Further, the cost estimates cannot be directly translated into benefits or resource savings due to obesity interventions, but these estimates can inform assessments of potential savings.

\section{Evidence of cost-utility and cost-effectiveness analyses and of valuations of benefits}

Once the decision to intervene in order to correct market inefficiencies is made (8), policymakers need a list of interventions to choose from to create a package of measures. Such interventions have to be both effective and provide good value for money (be efficient) in a particular context. As described above, CEAs/ CUAs are often used to assess the efficiency of a single intervention compared to an alternative. In general, only health-related benefits are considered, thus the perspective is essentially of a health sector, despite a general recognition that obesity needs to be addressed beyond the health sector. McKinnon et al. (31) provide the most recent systematic review of CEA/CUA of obesity prevention worldwide, while Lehnert et al. (32) review evidence for countries of the Organization for Economic Cooperation and Development (OECD). Others have conducted systematic reviews of economic evaluations (mostly CEAs/CUAs) of childhood obesity-related interventions (33-35). Interventions included in those reviews (31-35) were in the areas of community and built environment, nutrition-related policy/education changes, the school environment, and social marketing and media. Many studies in the reviews found beneficial economic outcomes of interventions. However, while many studies reported in the reviews modeled long-term impacts, most of the experienced-based assessments were from trials or observational studies over a relatively short horizon. Evidence of the long-term impact of interventions remains a research gap.

Countries of Latin America and the Caribbean (LAC) have been planning and piloting population-wide and targeted policy responses to obesity $(36,37)$. However, rigorous evaluations of effectiveness of those LAC obesity prevention and control measures have been sparse. Emerging evidence includes evaluations of a tax on sugar-sweetened beverages in Mexico (38), school-based programs in Latin America (39), obesity treatment interventions for children in Latin America (40), and physical activity interventions (41). Given the sparseness of evidence, earlier comprehensive nationwide studies, such as the 2010 CEA study by OECD and the World Health Organization (WHO) (42) for Mexico and Brazil, used global evidence on intervention effectiveness rather than evidence specific to the Americas. Similarly, the WHO menu of cost-effective interventions on noncommunicable diseases given in Appendix 3 of the Global Action Plan for the Prevention and Control of Noncommunicable Diseases 2013-2020 (43) is based on the global evidence of intervention effectiveness, for the most part in developed countries (44), rather than regionor country-specific evidence.

Further information on effectiveness and on intervention efficiency as provided by SCBA, CEA, or CUA is needed. Currently, CEA/CUA evidence for LAC countries is extremely limited $(2,4,36$, 45, 46).

The importance of valuing the benefits of obesity treatment and prevention in 
monetary units has been recognized, particularly to enable multisectoral analyses. However, only a few examples of such valuations exist, including for the United States (47), Germany (48), and Taiwan (49). As for valuing benefits of healthy populations in general, several approaches have been offered ("full income," "value of lost output," and "value of life"), and their applications are emerging (50). Outside the health sector, guidance exists to incorporate and value health impacts using a diversity of methods within the SCBA framework, e.g., willingness to pay $(16,51)$.

\section{Complementary economic evidence}

A limited number of projects worldwide have attempted to evaluate impacts of nutrition-related policies on GDP and economic sectors. Mukhopadhyay and Thomassin (52) studied the impact of changes in Canadians' diet on Canada's export and import of meat, dairy products, and fruits and vegetables. The OECD (53) examined the impact of a reduction in sugar on the agriculture sector and trade. Srinivasan et al. (54) quantified and valued the consumption impact of implementing WHO dietary norms. A World Economic Forum (WEF) report (50) provides examples of case studies that applied an SROI approach, including a grant for nutrition improvement in Singapore and its effect on coronary diseases. With this nutrition grant, benefits in QALYs were monetized using GDP per capita.

These various complementary studies illustrate how a broader scope of analysis could provide evidence to inform obesity-related multisectoral intervention decisions.

\section{Designing an intervention package}

Economic analyses of single interventions are useful, but they do not in themselves provide guidance for a national strategy for obesity prevention and control. To turn the rising tide of obesity, a comprehensive assessment of an intervention package in various settings and contexts is required, including potential synergies among chosen interventions and their scalability to a subnational or national level.

Several studies provide economic analysis of an intervention package at a national level with different degrees of methodological robustness. Table 2 provides summaries of these studies (42, 55-60). These studies recognize that a package should include both populationlevel and targeted interventions. Targets usually include children, obese individuals, or populations with low socioeconomic status. Considered intervention packages include health education, regulation, fiscal measures, individual counseling, medical treatment of obesity, healthy eating, and physical activity interventions in schools and worksites. Typically, assessed interventions require significant upfront investments, but only achieve impact after several years, such that at least five years of experience is needed for them to reach an acceptable level of cost-effectiveness. Interventions with the most favorable cost-effectiveness ratio at the population level are outside health care $(42,55,56)$. Individuallevel interventions on their own may take decades to reach a favorable cost-effectiveness ratio due to difficulties in reaching a large proportion of the population. In contrast, interventions in the environments that shape obesogenic behaviors (e.g., food labeling) have a modest individual effect, but are societally cost-effective because a modest effect is aggregated over an entire population, and implementation costs are relatively low.

A diverse package of complementary population-level interventions in obesogenic environments offers the most promising investment scenario for most country contexts. To support this, however, more evidence of a long-term effect of population-level interventions is needed. Further, global tobacco control experience shows that comprehensiveness and synergies are crucial for effectiveness (61). However, most integrated assessments for obesity action consider an overall effect of an intervention package as a sum of individual intervention effects, without consideration of crosseffects or synergies. We found only one study (42) that formally modeled a synergy effect.

Even if an intervention is effective at preventing obesity at reasonable cost (cost-effectiveness), other criteria influence decision-making. As preventive interventions are aimed at having a long-lasting effect, the majority of studies in Table 2 assess sensitivity of CEA results to the sustainability of an intervention effect. Also, the CEA/CUA-based studies in Table 2 apply criteria of equity, acceptability to stakeholders, feasibility of implementation, and scalability of interventions to a national level. Formal quantitative applications exist to incorporate these criteria in economic analysis (e.g., in the ACE study (56), a CEA was undertaken specifically for indigenous populations), or to apply afterwards. In most instances, however, when other criteria were formally considered, it was in the form of a qualitative assessment by a stakeholder committee. It is noteworthy that guidelines in areas outside health (such as with environment and public service programs) suggest clear, explicit approaches to incorporate equity into analysis $(16,51)$.

\section{DISCUSSION}

The landscape of studies concerning the investment case for obesity is dominated by CEA/CUA. Some of these analyses are broader than others in terms of the number of interventions assessed and the criteria for intervention ranking. Significant methodological differences across the studies that we reviewed (even among CUAs/CEAs) prevent a comparison of results. Thus, studies that assess a variety of interventions using the same approach are the most useful. Among CUAs that analyzed packages of intervention for national contexts, some analyses, such as Cecchini et al. (42) and ACE-Obesity (56), are based on rigorous epidemiological models incorporating uncertainty. Other CUA studies, such as McKinsey Global Institute (59), rely on intervention evidence from systematic reviews or from comprehensive studies. Several LAC countries have launched comprehensive packages of antiobesity interventions (4, 62). However, the evidence on these interventions' effectiveness is sparse, and economic analyses of the packages as a whole, including their synergetic effect, are as yet limited.

The scope of an investment case for obesity prevention and control is large, and many methodological and evidence gaps exist. Moving forward will require a concerted effort of researchers, evaluators, and surveillance experts. In the process of developing intervention and research projects, early involvement by economists and other social scientists is needed in order to collect relevant economic data and ensure rigorous economic analysis. Table 3 summarizes two things: 1) gaps in current methods and 


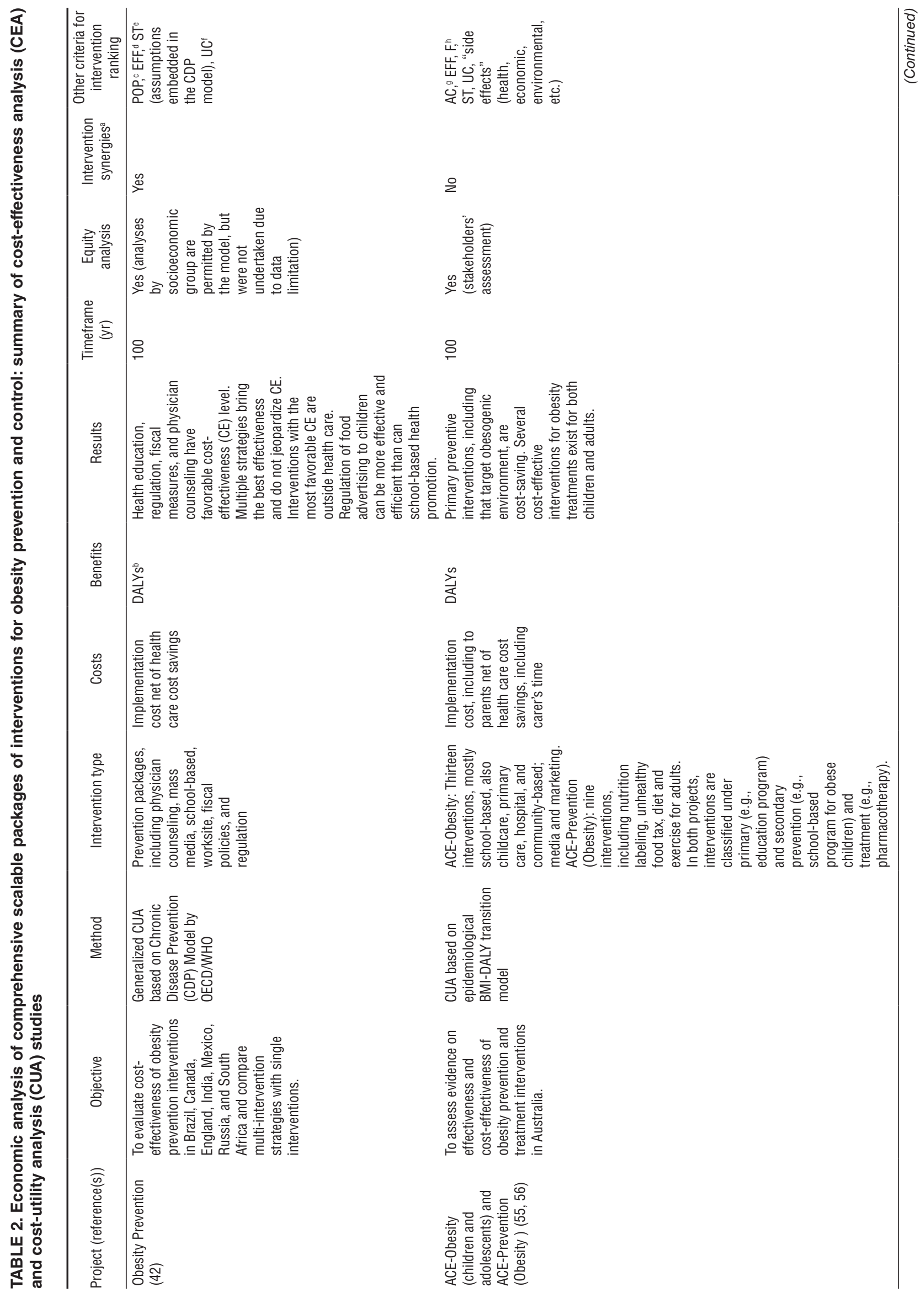




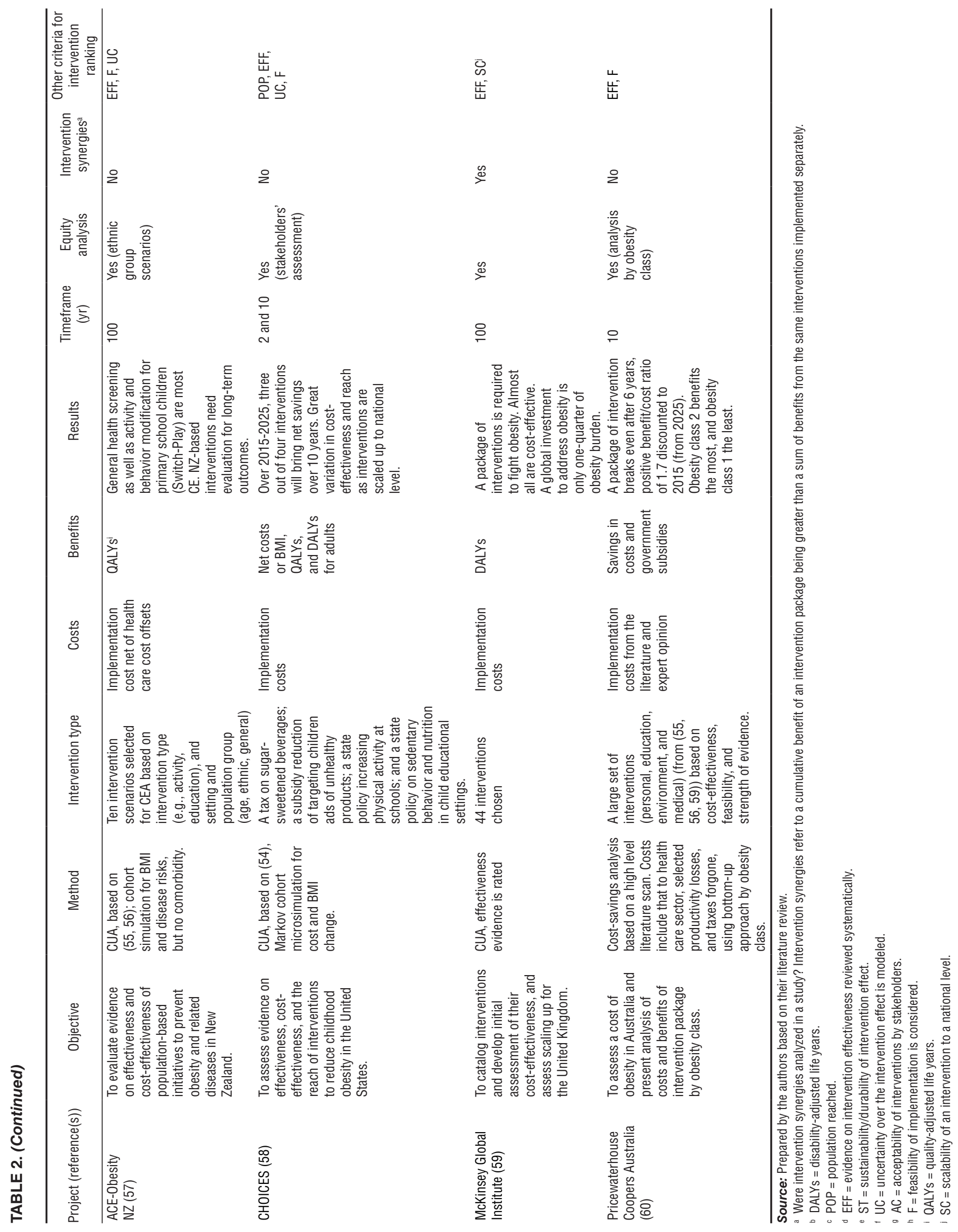


TABLE 3. Considerations and ways forward in methods and evidence for economic analysis of obesity prevention and control

\begin{tabular}{|c|c|}
\hline Considerations & Ways forward \\
\hline $\begin{array}{l}\text { Quality-adjusted life years (QALYS) do not capture what nonhealth stakeholders value } \\
\text { in health improvements. Given that obesity policies often concern nonhealth sectors, } \\
\text { this is, at present, an important weakness of a cost-effectiveness and cost-utility } \\
\text { analyses (CEAs/CUAs) as applied to public health. }\end{array}$ & $\begin{array}{l}\text { Develop consistent approaches to value benefits of interventions in a common } \\
\text { currency acceptable to all sectors of the economy. Two approaches to valuing } \\
\text { statistical life (VSL) are common and can potentially be adopted for valuations of } \\
\text { antiobesity interventions, and public health interventions, in general. These are } \\
\text { revealed preferences and contingent valuation approaches. }\end{array}$ \\
\hline $\begin{array}{l}\text { QALY metrics focus on the at-risk individual. Obesity, particularly childhood obesity, } \\
\text { and related interventions often impact families and other caregivers. These effects }\end{array}$ & $\begin{array}{l}\text { Incorporate effects on families and other caregivers (as applicable) into intervention } \\
\text { benefits. }\end{array}$ \\
\hline
\end{tabular}
CEA/CUA.

Impacts on socioeconomic and other inequalities have been recognized as important criteria when ranking interventions. Currently, distributional consequences of an intervention and how it impacts various population groups are, with few exceptions (e.g., (56)), rarely accounted for. Improvements in terms of QALYs are assumed to be the same across the whole population, and QALY metrics are based on the general population.

A need for a transparent ranking based on chosen criteria, beyond effectiveness and efficiency of an intervention package, has been identified by several comprehensive studies (e.g., $(42,56))$.

QALYs are computed on a life-time basis, but the evidence on effectiveness of interventions is often short term.

Recent advances in behavioral economics have implications for a conceptual framework of social cost-benefit analysis (SCBA) and its applications (8). Behavioral economics is exploring the behavioral implications of relaxing various traditional assumptions about individual choice. When individuals' preferences for products or activities, risk aversion, or discount rates are not constant through time, traditional discounting of future net social benefits under SCBA can give incorrect results. For example, QALY calculations are not consistent with hyperbolic discounting by an individual. (Hyperbolic or "present-based" discounting refers to preferences for immediate gratification or to extreme short-term aversion to risk, where the discount rate drops sharply when looking at the long horizon.)

Many observational studies, particularly in the past, have been measuring associations rather than causal effects, e.g., between physical activity and body mass index (BMI). It is clear that the attribution of the effect is required to appropriately measure the effect of various factors and of interventions on obesity and health.

Develop approaches to incorporate equity considerations into investment cases for obesity.

Develop new or modify existing approaches to consistently rank interventions upon chosen criteria. These could then provide a foundation for an integrated investment case model that draws epidemiological outcomes from existing models, applies economic (efficiency) considerations, and ranks interventions according to specified criteria.

Due to the fact that benefits of most obesity interventions occur over a long time, trial-based studies with a short-term follow-up need to be supported either by a longitudinal cohort study or a modeling framework, which simulate long-term epidemiological outcomes of interventions. This permits accounting for long-term benefits of interventions on obesity, as well as assessing how uncertainty in the sustainability of the benefit affects CEA results.

How the two discounting rates can be reconciled is an open area of research (8).

Various techniques, including lagged variable and instrumental variable approaches, exist to devise a causal effect. For example, these have been applied in studies examining the effect of BMI on individual's wages (63). measurence

Globally, including in Latin America and the Caribbean (LAC), epidemiological data and economic data are both limited, which impedes economic analyses and evidencebased policy planning.

Improve data and data collection infrastructure to enable evidence on: 1) health risks over time; 2) health care and other costs associated with living with a particular disease and comorbid conditions; 3 ) effectiveness of interventions in isolation or as comprehensive packages for specific countries/regions; 4) sustainability of intervention effects over time; 5 ) cost-effectiveness of interventions.

Cumulative effects of multi-intervention strategies could be very significant. However, little evidence exists on synergies. Most estimates of impact are calculated as a sum of effects of individual interventions.

In several LAC countries, evidence on economic costs of obesity is scarce or estimates vary widely.

As countries introduce packages of interventions, economic analyses have to take account of the synergetic effect of the package and take care in the attribution of an observable effect to a particular intervention from the package.

Expand economic analysis and methods to capture broader costs of obesity, including costs to various economic actors and types of costs (e.g., health care, productivity, to human capital).

Economic evidence emerges on the impact of nutrition-based policies, as shown in Table 2 (complimentary analyses). Economic analyses of industrial policies that have significant effect on access and availability of healthy and unhealthy foods are needed.

It has been recognized that various interventions have to be implemented in concert to have a significant effect. The list of interventions should be broad enough for various actors to choose from to implement in their particular context.

Expand economic analysis of industrial policies that have significant health effects, e.g., agriculture, agri-food, and trade policies.

Expand the potential list of policies/instruments (and research on their effectiveness) to include: 1 ) incentives provided by various nonhealth policies and regulations, e.g., workplace policies; 2) policies and regulations at macro, micro, regional, and local levels; and 3 ) behavioral incentives (such as commitment mechanisms), changing defaults, and simplifying information (e.g., front-package traffic-light labeling) to make healthy choices easier.

Source: Prepared by the authors based on their literature review. 
evidence that impede the development of comprehensive investment cases for obesity prevention and control and 2) ways forward $(8,42,56,63)$.

On the methodological side, developing applications of existing methods for the monetary valuation of benefits will be essential to gain multisectoral support for obesity prevention and control. Although we found no studies that monetized health and other benefits of a comprehensive intervention package to address obesity, valuations of benefits from reduced obesity have been attempted (47-49), and associated methods are part of government agencies' guidelines for economic analyses $(16,51)$.

The subsection above on designing an intervention package outlines criteria other than economic efficiency that are important for decision-making. Among these are equity considerations, including the impact on the most vulnerable populations; feasibility and scalability of an intervention at a population level; and acceptability to various stakeholders. Transparent and consistent approaches for integrating these considerations into an investment case are required to improve decision-making and gain multisectoral buy-in. Here, guidelines and practical applications used by other sec- tors could be helpful for developing approaches with broad acceptance.

On the evidence side, progress is impeded by a lack of data and data infrastructure. This is shown not only by limited economic analyses of strategies implemented to address obesity throughout the Americas, but also by a paucity of evidence on intervention effectiveness in general, and on the cost of obesity to economies within LAC in particular. Evidence needs to be expanded to include prospective and retrospective economic evaluation of intervention packages, and to incorporate the broader costs of obesity, including impacts on diverse economic actors. While there may be opportunities for researchers to better utilize existing datasets, national authorities will likely need to invest in integrating economic data into public health surveillance infrastructure or surveys, including linkage or collection of new economic data, to support evidence-based policies. In the interim, countries can learn and extrapolate from their regional neighbors and adapt successful interventions to their context.

In practice, an investment case will differ from one jurisdiction to another, based on the perspective of analysis and the data in hand. Moreover, the choice of the most effective policy suite for a specific national context will be determined by a number of factors. These include the country-specific epidemiological profile, structure of the economy, dependence on trade, evidence on market failures, and distributional issues.

Acknowledgments. This paper has been facilitated by a discussion at a thematic working group virtual meeting and comments from participants of the in-person meeting on Advancing Economics for Prevention and Control of Noncommunicable Diseases in the Americas organized by PAHO in 2016. The authors thank John Cawley, Michele Cecchini, guest editors, and anonymous referees for their valuable comments.

Funding. The authors are employees of the Government of Canada.

\section{Conflicts of interest. None declared.}

Disclaimer. The views expressed in this manuscript do not necessarily reflect those of the Government of Canada, and may not necessarily reflect the opinion or policy of the RPSP/PAJPH or PAHO.

\section{REFERENCES}

1. Pan American Health Organization. Plan of Action for the Prevention of Obesity in Children and Adolescents. Washington, D.C.: PAHO; 2015. Available at: http:// www.paho.org $/ \mathrm{hq} /$ index.php?option= com_content\&view $=$ article\&id $=11373 \%$ 3Aplan-of-action-prevention-obesity-children-adolescents \& catid $=8358 \% 3 \mathrm{Aob}-$ esity\&Itemid $=4256 \&$ lang $=$ en Accessed 15 January 2018.

2. Caribbean Public Health Agency. Safeguarding our future development. Plan of action for promoting healthy weights in the Caribbean: Prevention and control of childhood obesity 2014-2019. Available at: http://carpha.org/downloads/HealthyWeights.pdf Accessed 15 January 2018.

3. Public Health Agency of Canada. Curbing childhood obesity: A Federal, provincial and territorial framework for action to promote healthy weights 2011. Available at: https://www.canada.ca/en/publichealth/services/health-promotion / healthy-living/curbing-childhood-obesity-federal-provincial-territorial-framework/curbing-childhood-obesityoverview-federal-provincial-territorialframework-action-promote-healthyweights.html Accessed 10 October 2017.
4. Barquera S, Campos I, Rivera JA. Mexico attempts to tackle obesity: the process, results, push backs and future challenges. Obes Rev. 2013;14(S2):69-78.

5. World Health Organization. UN Interagency Task Force on NCDs (UNIATF). Available at: http://www. who.int/ncds/un-task-force/en / Accessed 15 January 2018

6. Nugent R. Review of methods for NCD investment cases. Presentation at: Advancing Economics for the Prevention and Control of NCDs in the Americas. Washington, D.C. 2016 Aug 31-Sept 1.

7. World Health Organization. Investing in mental health: evidence for action. Geneva: WHO; 2013.

8. Ellis VL, Milliken OV. Integrating economics into the rationale for multisectoral action on obesity. Rev Panam Salud Publica. 2018;42: e58. https://doi.org/10.26633/RPSP.2018.58

9. Drummond MF, Sculpher GL, Torrance GW, O'Brien BJ, Stoddart GL. Methods for the economic evaluation of health care programmes. 3d ed. New York: Oxford University Press; 2005.

10. World Health Organization. Economic evaluation of childhood obesity. In: World Health Organization. Consideration of the evidence on childhood obesity for the
Commission on Ending Childhood Obesity: report of the Ad Hoc Working Group on Science and Evidence for Ending Childhood Obesity, Geneva, Switzerland. Geneva: WHO; 2016:37-43. Available at: http:/ / apps.who.int/iris/bitstre am/10665/206549/1/9789241565332_ eng.pdf Accessed 15 January 2018.

11. Brazier J, Ratcliffe J, Saloman J, Tsuchiya A. Measuring and valuing health benefits for economic evaluation. New York: Oxford University Press; 2017.

12. Banke-Thomas AO, Madaj B, Charles A, van den Broek N. Social return on investment (SROI) methodology to account for value for money of public health interventions: a systematic review. BMC Public Health. 2015;15(1):582.

13. UK Cabinet Office, The Office of the Third Sector. A guide to social return on investment 2012. Available at: https://www. bond.org.uk/data / files / Cabinet_office_A_guide_to_Social_Return_on_ Investment.pdf Accessed 8 January 2018.

14. Sassi F. Calculating QALYs, comparing QALY and DALY calculations. Health Policy Plan. 2006;21(5):402-8.

15. Food and Agriculture Organization of the United Nations. Tool for designing, monitoring and evaluating land 
administration programmes in Latin America. Available at: http://www.fao. org/in-action/herramienta-administracion-tierras/module-5/practical-evaluation-guide/introduction-cba/en/ Accessed 8 January 2018.

16. National Center for Environmental Economics, Office of Policy, U.S. Environmental Protection Agency. Guidelines for preparing economic analyses 2014. Available at: https://www.epa.gov/environmental-economics/guidelinespreparing-economic-analyses Accessed 15 January 2018.

17. Navrud S, Lindhem H. Valuing mortality risk reduction in regulatory analysis of environmental, health and transport policies: policy implications. Available at: http://www.oecd.org/env/tools-evaluation/49447312.pdf Accessed 8 January 2018.

18. Astolfi R, Lorenzoni L, Oderkirk J. Informing policy makers about future health spending: a comparative analysis of forecasting methods in OECD countries. Health Policy. 2012;107(1):1-10.

19. Tremmel M, Gerdtham U, Nilsson PM, Saha S. Economic burden of obesity: a systematic literature review. Int J Environ Res Public Health. 2017;14(4):435.

20. Cuadrado C. Projecting costs of obesity in Chile (and Latin-America): data and method issues. Presentation at: Advancing Economics for the Prevention and Control of NCDs in the Americas; Washington, D.C.; 2016 Aug 31-Sept 1.

21. Anis AH, Zhang W, Bansback N, Guh D, Amarsi Z, Birmingham C. Obesity and overweight in Canada: an updated cost-ofillness study. Obes Rev. 2010;11(1):31-40.

22. Krueger H, Turner D, Krueger J, Ready AE. The economic benefits of risk factor reduction in Canada: tobacco smoking, excess weight and physical inactivity. Can J Public Health. 2014;105(1):e69-e78.

23. Tsai AG, Williamson DF, Glick HA. Direct medical cost of overweight and obesity in the USA: a quantitative systematic review. Obes Rev. 2011;12(1):50-61.

24. Dee A, Kearns K, O'Neill C, Sharp L, Staines A, O'Dwyer V, et al. The direct and indirect costs of both overweight and obesity: a systematic review. BMC Res Notes. 2014;7(1):242

25. Trogdon J, Finkelstein E, Hylands T, Dellea P, Kamal-Bahl S. Indirect costs of obesity: a review of the current literature. Obes Rev. 2008;9(5):489-500.

26. Smith E, Hay P, Campbell L, Trollor JN. A review of the association between obesity and cognitive function across the lifespan: implications for novel approaches to prevention and treatment. Obes Rev. 2011; 12(9):740-55.

27. Etienne CF. Malnutrition in the Americas: challenges and opportunities. Rev Panam Salud Publica. 2016;40(2):102-3.

28. Economic Commission for Latin America and the Caribbean; World Food Programme. The cost of the double burden of malnutrition: social and economic impact. Summary of the pilot study in Chile, Ecuador and Mexico. Available at: http:/ / es.wfp.org/sites/default/files / es/file/english_pilotstudy_april_2017. pdf Accessed 15 January 2018.

29. Krzizek E, Brix JM, Herz CT, Kopp HP, Schernthaner G, Schernthaner G, et al. Prevalence of micronutrient deficiency in patients with morbid obesity before bariatric surgery. Obes Surg. 2018;28(3): 643-8.

30. Via M. The malnutrition of obesity: micronutrient deficiencies that promote diabetes. ISRN Endocrinol. 2012;2012:103472. doi: $10.5402 / 2012 / 103472$.

31. McKinnon RA, Siddiqi SM, Chaloupka FJ, Mancino L, Prasad K. Obesity-related policy/environmental interventions: a systematic review of economic analyses. Am J Prev Med. 2016;50(4):543-49.

32. Lehnert T, Sonntag D, Konnopka A, Riedel-Heller S, König H. The long-term cost-effectiveness of obesity prevention interventions: systematic literature review. Obes Rev. 2012;13(6):537-53.

33. Döring N, Mayer S, Rasmussen F, Sonntag D. Economic evaluation of obesity prevention in early childhood: methods, limitations and recommendations. Int J Environ Res Public Health. 2016;13(9):911.

34. John J, Wenig CM, Wolfenstetter SB. Recent economic findings on childhood obesity: cost-of-illness and cost-effectiveness of interventions. Curr Opin Clin Nutr Metab Care. 2010 May;13(3):305-13.

35. John J, Wolfenstetter SB, Wenig CM. An economic perspective on childhood obesity: recent findings on cost of illness and cost effectiveness of interventions. Nutrition. 2012;28(9):829-39.

36. Kline L, Jones-Smith J, Jaime Miranda J, Pratt M, Reis R, Rivera J, et al. A research agenda to guide progress on childhood obesity prevention in Latin America. Obes Rev. 2017;18(S2):19-27.

37. University of the West Indies; Caribbean Public Health Agency; Healthy Caribbean Coalition; University of Toronto. Accelerating action on NCDs. Evaluation of the 2007 CARICOM heads of government Port of Spain NCD summit declaration. Report on behalf of $\mathrm{PAHO} / \mathrm{WHO}$ and CARICOM. Available at: http://onecaribbeanhealth.org/wp-content/uploads / 2016/10/ACCELERATINGACTION-ON-NCDS-POSDEVALReport-1.pdf Accessed 8 January 2018.

38. Colchero MA, Rivera-Dommarco J, Popkin $\mathrm{BM}, \mathrm{Ng}$ SW. In Mexico, evidence of sustained consumer response two years after implementing a sugar-sweetened beverage tax. Health Aff (Millwood). 2017 Mar 1;36(3):564-571.

39. Lobelo F, Garcia de Quevedo I, Holub CK, Nagle BJ, Arredondo EM, Barquera S, et al. School-based programs aimed at the prevention and treatment of obesity: evidence-based interventions for youth in Latin America. J Sch Health. 2013;83(9): 668-77.

40. Nagle BJ, Holub CK, Barquera S, SánchezRomero LM, Eisenberg CM, RiveraDommarco JA, et al. Interventions for the treatment of obesity among children and adolescents in Latin America: a systematic review. Salud Publica Mex. 2013;55: 434-40.

41. Salvo D, Reis RS, Sarmiento OL, Pratt M. Overcoming the challenges of conducting physical activity and built environment research in Latin America: IPEN Latin America. Prev Med. 2014;69:S86-S92.

42. Cecchini M, Sassi F, Lauer JA, Lee YY, Guajardo-Barron V, Chisholm D. Tackling of unhealthy diets, physical inactivity, and obesity: health effects and cost-effectiveness. Lancet. 2010;376(9754):1775-84.

43. World Health Organization. Updating Appendix 3 of the Global NCD Action Plan 2013-2020. Available at: http:/ / www.who. int/ncds/governance / appendix3update/en/ Accessed 10 November 2017.

44. World Health Organization. Consultation on Updating Appendix 3 of the Global NCD Action Plan 2013-2020. Available at: http://who.int/nmh/events/meeting-report-consultation-on-appendix-3-final. pdf?ua=1 Accessed 10 November 2017.

45. Barquera S. Obesity prevention. Salud Publica Mex. 2013;55 Suppl 3:356.

46. Montes F, Sarmiento OL, Zarama R, Pratt M, Wang G, Jacoby E, et al. Do health benefits outweigh the costs of mass recreational programs? An economic analysis of four Ciclovía programs. J Urban Health. 2012;89(1):153-70.

47. Cawley J. Contingent valuation analysis of willingness to pay to reduce childhood obesity. Econ Hum Biol. 2008;6(2):281-92.

48. Kesztyüs D, Lauer R, Schreiber AC, Kesztyüs T, Kilian R, Steinacker JM. Parents' willingness to pay for the prevention of childhood overweight and obesity. Health Econ Rev. 2014;4(1):20.

49. Fu T, Lin Y, Huang CL. Willingness to pay for obesity prevention. Econ Hum Biol. 2011;9(3):316-24.

50. World Economic Forum; Bain \& Company. Maximizing healthy life years: investments that pay off. Available at: http:// www3.weforum.org / docs / WEF Maximizing_Healthy_Life_Years.pdf Accessed 15 January 2018.

51. HM Treasury. The Green Book; appraisal and evaluation in central government. Available at: https://www.gov.uk/government/publications / the-greenbook-appraisal-and-evaluation-in-central-governent Accessed 15 January 2018.

52. Mukhopadhyay K, Thomassin PJ. Economic impact of adopting a healthy diet in Canada. J Public Health. 2012;20(6): 639-652.

53. Organisation for Economic Co-operation and Development. The market implications of reduced sugar consumption. (Agriculture Policy Note March 2017). Available at: https://www.oecd.org/tad/ policynotes/The-market-implications-ofreduced-sugar-consumption.pdf Accessed 15 January 2018.

54. Srinivasan CS, Irz X, Shankar B. An assessment of the potential consumption impacts of WHO dietary norms in OECD countries. Food Policy. 2006;31(1):53-77.

55. Haby M, Vos T, Carter R, Moodie M, Markwick A, Magnus A, et al. A new approach to assessing the health benefit from 
obesity interventions in children and adolescents: the assessing cost-effectiveness in obesity project. Int JObes. 2006;30(10):1463.

56. Carter R, Moodie M, Markwick A, Magnus A, Vos T, Swinburn B, et al. Assessing cost-effectiveness in obesity (ACEObesity): an overview of the ACE approach, economic methods and cost results. BMC Public Health. 2009;9(1):419.

57. Mernagh P, Paech A, Coleman K, Weston A, McDonald J, Cumming J, et al. Assessing the cost-effectiveness of public health interventions to prevent obesity: overview report. Wellington: Health Research Council of New Zealand; 2010.

58. Gortmaker SL, Long MW, Resch SC, Ward ZJ, Cradock AL, Barrett JL, et al.
Cost effectiveness of childhood obesity interventions: evidence and methods for CHOICES. Am J Prev Med. 2015;49(1): $102-11$.

59. Dobbs R, Sawers C, Thompson F, Manyika J, Woetzel J, Child P, et al. Overcoming obesity: an initial economic analysis. Available at: https://www.mckinsey. $\mathrm{com} /$ industries/healthcare-systems-andservices / our-insights / how-the-worldcould-better-fight-obesity Accessed 15 January 2018.

60. PricewaterhouseCoopers. Weighing the cost of obesity: a case for action. Available at: https://www.pwc.com.au/pdf/weighingthe-cost-of-obesity-final.pdf Accessed 8 March 2018.
61. World Health Organization. WHO Framework Convention on Tobacco Control. Geneva: WHO; 2003.

62. Caballero B, Vorkoper S, Anand N, Rivera J. Preventing childhood obesity in Latin America: an agenda for regional research and strategic partnerships. Obes Rev. 2017;18(S2):3-6.

63. Cawley J. The impact of obesity on wages. J Hum Resour. 2004;39(2):451-74.

Manuscript received on 19 October 2017. Revised version accepted for publication on 22 January 2018

RESUMEN Este artículo abre un debate sobre las principales características de los argumentos a favor de la inversión para prevenir y controlar la obesidad, al buscar evidencia sobre los métodos existentes y destacar las consideraciones relativas al contexto y la evidencia para América Latina y el Caribe. Instamos a los investigadores y analistas en el campo a que actualicen y amplíen los métodos existentes de análisis económico a fin de reflejar mejor la naturaleza multisectorial de los argumentos a favor de la inversión para la prevención y el control de la obesidad. También encontramos lagunas en la investigación y el trabajo adicional que se requiere para impulsar los métodos y la evidencia que respalden estos argumentos a favor de la inversión en toda América.

Palabras clave

Análisis costo-beneficio; obesidad; inversiones en salud; economía de la salud; política de salud; Américas.

RESUMO

Elaboração de um caso de investimento para prevenção e controle da obesidade: perspectivas sobre o progresso metodológico e evidências

Palavras-chave
Esta análise visa trazer à discussão as principais características de um caso de investimento para prevenção e controle da obesidade ao examinar comprovações sobre os enfoques existentes e destacar considerações contextuais e evidências para a América Latina e o Caribe. Fazemos um chamado aos pesquisadores e analistas no campo a atualizar e expandir a metodologia atual de análise econômica a fim de melhor refletir o caráter multissetorial de um caso de investimento para prevenção e controle da obesidade. Também identificamos lacunas de pesquisa e a necessidade de trabalhar mais para melhorar a metodologia e as evidências de casos de investimento nas Américas.

Análise custo-benefício; obesidade; investimentos em saúde; economia da saúde; política de saúde; Américas. 